\title{
PERCEPÇÕES DA EQUIPE DE ENFERMAGEM ACERCA DA VIOLÊNCIA DOMÉSTICA CONTRA A MULHER
}

\author{
Ana Paula Cunha Duarte'; Kelly Rose Pinho Moraes²; Geovane Moura Viana ${ }^{3}$; Linielce \\ Portela Nina ${ }^{4}$; Joana Maria Machado Mendes5; Antônia Katia Lopes Araújo ${ }^{6}$; Dheymi Wilma \\ Ramos Silva ${ }^{7}$; Caroline Natielle Rocha da Silva ${ }^{8}$.
}

1,2,3,4,5,6 Graduados em Enfermagem Bacharelado, Universidade Estadual do Maranhão (UEMA), Coroatá, Maranhão. ${ }^{7}$ Mestre em Biodiversidade, Ambiente e Saúde, pela a Universidade Estadual do Maranhão (UEMA), Caxias, Maranhão. Graduada em Enfermagem Bacharelado, Universidade

Estadual do Maranhão (UEMA), Caxias, Maranhão; ${ }^{8}$ Especialização em Estratégia de Saúde da Família pela Sociedade de Ensino Superior Estácio de Ribeirão Preto LTDA (UNISEB), Ribeirão Preto, São Paulo. Graduação em Enfermagem pela Faculdade de Educação São Francisco (FAESF), Pedreiras, Maranhão.

DOI: $10.47094 /$ ICONRES.2021/23

\begin{abstract}
RESUMO
De acordo com a Organização mundial de saúde (OMS), o Brasil possui grandes índices de violência, se tornando um dos países mais violentos do globo. Só nas últimos décadas, cerca de 553 mil pessoas vieram a óbito devido à violência intencional. Sabe-se que muitas dessas agressões podem acontecer em âmbito doméstico. Este estudo objetivou conhecer a percepção da equipe de enfermagem acerca da violência doméstica contra a mulher. Sendo uma revisão da literatura brasileira, realizada entre os meses de dezembro de 2020 e janeiro de 2021, nas principais bases de dados da Biblioteca Virtual de Saúde. Constatou-se através da leitura aprofundada dos artigos selecionados, que os profissionais possuem uma visão limitada acerca da violência contra a mulher, considerando as capacitações e treinamentos como estratégias importantes para se qualificarem e prestarem um melhor atendimento.
\end{abstract}

PALAVRAS-CHAVES: Violência doméstica; Violência contra a mulher; Enfermagem.

ÁREA TEMÁTICA: Saúde Coletiva 


\section{INTRODUÇÃO}

O Brasil é um dos países mais violentos do mundo, possuindo índices alarmantes. Em relação a violência contra a mulher (VCM), não é diferente, só em 2018, de acordo com o Fórum Brasileiro de Segurança Pública (FBSP), foram registrados mais de 60 mil casos de violência sexual no Brasil. Já o Sistema de Informação de Agravos de Notificação (SINAN) no mesmo ano registrou 27.439 notificações de violência sexual ou estupro no âmbito do Sistema Único de Saúde (SUS) (BRASIL, 2020). Vale ressaltar que muitas dessas agressões físicas e abusos podem acontecem no ambiente doméstico, e que muitas vezes essas vítimas não são atendidas em unidades de saúde, pois não procuram por medo ou vergonha do ocorrido, o que prejudica os dados, gerando uma subnotificação (CERQUEIRA et al., 2018; BUENO et al., 2019). A equipe de enfermagem pode desempenhar um papel significativo na identificação, bem como na assistência e cuidado a mulheres vítimas de violência doméstica (MVVD), pois são profissionais que estão mais próximos aos pacientes, o que o leva a uma posição de destaque na promoção de ações e detecção precoce desses casos, bem como em seu acompanhamento, notificação, orientação e prevenção (ACOSTA et al., 2018; MINAYO et al., 2018). Neste interim, o presente trabalho objetivou conhecer a percepção da equipe de enfermagem, acerca da violência doméstica contra a mulher (VDCM).

\section{METODOLOGIA}

Trata-se de uma pesquisa de revisão integrativa da literatura brasileira, compreendendo uma busca nas bases de dados da Biblioteca Virtual de Saúde, nos bancos de dados Scielo, BDENF, e Portal de Periódicos da CAPES, no período de Dezembro de 2020 a Janeiro de 2021, com o auxílio dos descritores: Violência doméstica; Violência contra a mulher; Enfermagem e o operador booleano “AND”. Foram levantadas e analisados 20 publicações no período de 2016 a 2020, destas foram excluídas as que estavam fora do limite temporal exigido, e que não atendiam ao objetivo geral da pesquisa, assim, 11 artigos tiveram seus resultados sintetizados descritivamente e discutidos nos resultados do estudo.

\section{FUNDAMENTAÇÃO TEÓRICA}

A Violência contra a mulher (VCM) é conceituada pela a Organização dos Estados Americanos (OEA) desde 1994 como "qualquer ação ou conduta, baseada no gênero, que cause morte, dano ou sofrimento físico, sexual ou psicológico à mulher, tanto no âmbito público como privado" (OEA, 1995, p. 2). Já a Lei brasileira n 11.340 de 2006, considera a violência doméstica (VD) e familiar contra a mulher como "qualquer ação ou omissão baseada no gênero que lhe cause morte, lesão, sofrimento físico, sexual ou psicológico e dano moral ou patrimonial” (BRASIL, 2006, p. 5). A VDCM pode ocorrer de várias formas, sendo violência física, que pode ser qualquer conduta que possa ofender a integridade física da mulher; a violência psicológica, sendo considerada qualquer conduta que lhe cause prejuízos a saúde mental ou viole sua intimidade; Violência sexual, 
entendida como qualquer conduta que possa intimidar ou forçar a mulher a manter relações sexuais não consentidas; A violência patrimonial, que corresponde a qualquer conduta que retenha seus bens, como instrumentos de trabalho, documentos pessoais, ou recursos econômicos; e a violência moral, que engloba calúnias, difamação ou injúrias. A VDCM também pode ser dividida em três fases: a fase de tensão, que vai desde agressões verbais a agressões físicas leves e provocações; a segunda fase, que são as agressões físicas graves; e a última fase, em que o agressor se arrepende dos atos praticados, reiniciando o ciclo violento. Em todo o mundo a VD é um problema de saúde pública, no Brasil, não é diferente, e em decorrência disso foram instituídas algumas leis e portarias para o seu combate de forma efetiva e multidisciplinar, integrandos os órgãos de justiça, saúde, serviços sociais e segurança pública (NASCIMENTO et al., 2019; PIRES et al., 2019). Desta forma, vê-se que é importante que os profissionais de saúde, como os profissionais de enfermagem, que estão inseridos na equipe multiprofissional de estabelecimentos de saúde público ou privado, conheçam as bases legais de atendimento à mulher, incluindo as leis e portarias voltadas às mulheres vítimas de VD, para que consigam identificar, notificar e proporcionar um atendimento humanizado e integral, como por exemplo a lei de $n^{\circ} 12.845$ de 2013, conhecida como Lei do Minuto Seguinte, que dispõe sobre o atendimento integral a vítimas de violência sexual, na qual hospitais devem oferecer atendimento integral e emergencial através do tratamento profilático da gravidez e de Infecções Sexualmente Transmissíveis (IST) (BRASIL, 2013). Mulheres vítimas de violência doméstica, por vezes não relatam o ocorrido aos profissionais de saúde que lhes prestam assistência, chegando aos serviços de saúde e relatando outras queixas. Tal atitude além de dificultar a identificação e notificação de casos de violência, também interfere na implementação de ações para o enfrentamento e reflexões sobre o problema (MINAYO et al., 2020; PROCENTESE et al., 2019). Muitos profissionais, ainda entendem que a VCM é um problema que pode ser resolvido apenas por agentes judiciários, não sendo pertinente ao campo da saúde, esquecendo-se da responsabilidade do setor da saúde com os direitos humanos. Além disso, alguns profissionais veem dificuldades para lidar com esse problema, pois envolve muitas questões socioculturais, tornando difícil, inclusive, a identificação das vítimas (SILVA et al., 2020). É fato que a maior parte dos profissionais de enfermagem ainda não estão preparados para lidar com o problema da VD, principalmente por falta de informação ou treinamento. Isto reflete muitas vezes no julgamento das vítimas, que recebem tratamento apenas das feridas físicas da violência, e em seguida, são encaminhadas para outros serviços considerados mais adequados e não recebem atendimento voltado à sua saúde mental (XAVIER et al., 2017; MOTA et al., 2020). Estudo de Cortes et al (2016) relata que é comum que se faça somente o que está prescrito, o que caracteriza uma assistência unicamente clínica. O ideal, na verdade, é um cuidado clínico de enfermagem, acompanhado de escuta e diálogo que, além de um meio de enfrentamento, também tranquiliza a mulher.

\section{CONCLUSÃO}

Conclui-se que vários estudos mostram que a percepção da equipe de enfermagem acerca da VDCM ainda é limitada, o que impossibilita a identificação das vítimas. Muitas vezes esses profissionais associam a violência a agressões físicas e psicológicas, atribuindo como principais causas 
fatores socioculturais. Aliado a isso, também pode contribuir para a não identificação e subnotificação, questões relacionadas ao treinamento e falta de informação. Para isto, é extremamente necessário que os profissionais estejam preparados para notificar casos de VD assim que perceberem ou que tiverem conhecimento do ocorrido, e que estejam dispostos a serem coparticipantes no processo de apoio, combate à violência e reintegração da mulher. Salienta-se que a temática abordada neste estudo necessita de mais debates e investimentos, de forma a qualificar e informar os profissionais de saúde e de áreas afins, pois é um problema social e de saúde pública, que merece atenção especial e sensibilidade por parte dos profissionais que atendem ou que podem vir a atender uma mulher vítima de violência. Com isso, sugere-se que novos estudos sobre a temática, principalmente estudo qualitativos, que possam saber a sejam realizados, de forma a ampliar os conhecimentos e as evidências científicas acerca da violência doméstica contra a mulher.

\section{REFERÊNCIAS}

ACOSTA, D.F.; GOMES, V.L.O.; OLIVEIRA, D.C.; MARQUES, S.C.; FONSECA, A.D. Representações sociais de enfermeiras acerca da violência doméstica contra a mulher: estudo com abordagem estrutural. Revista Gaúcha de Enfermagem, Porto Alegre, v. 39, p. e61308, jul. 2018. Disponível em: https://www.scielo.br/pdf/rgenf/v39/1983-1447-rgenf-39-e61308.pdf. Acesso em: 23 dez. 2020.

BRASIL. Lei $\mathbf{n}^{\mathbf{0}} \mathbf{1 1 . 3 4 0}$, de 7 de agosto de 2006. Cria mecanismos para coibir a violência doméstica e familiar contra a mulher. Cria mecanismos para coibir a violência doméstica e familiar contra a mulher. Brasília (DF): 2006. Disponível em: http:/www.planalto.gov.br/ccivil_03/_ato20042006/2006/lei/111340.htm. Acesso em: 12 dez. 2020.

BUENO, S. Anuário Brasileiro de Segurança Pública 2019. Fórum Brasileiro de Segurança Pública, São Paulo, v. 13, p. 8-226, jun. 2019. Disponível em: https://forumseguranca.org.br/anuario-13/. Acesso em: 30 dez. 2020.

CERQUEIRA, D.; LIMA, R.S.D.; BUENO, S.; VALENCIA, L.I.; HANASHIRO, O.; MACHADO, P.H.G.; LIMA, A.D.S. Atlas da Violência. Mapeia os homicídios no Brasil. IPEA e FBSP, Rio de Janeiro, p. 27-51, 2018. Disponível em: https://www.ipea.gov.br/portal/images/stories/PDFs/ relatorio_institucional/180604_atlas_da_violencia_2018.pdf. Acesso em: 05 jan. 2021.

CORTES, L.F.; PADOIN, S.M.M; KINALSKI, D.D.F. Instrumentos para articulação da rede de atenção às mulheres em situação de violência: construção coletiva. Revista Gaúcha de Enfermagem, v. 37, n. esp., p. e2016-0056, jun. 2016. Disponível em: https://www.scielo.br/pdf/rgenf/v37nspe/01026933-rgenf-1983-14472016esp2016-0056.pdf. Acesso em: 28 dez. 2020.

Ministério da Saúde. Dados Epidemiológicos Sinan. 2020. Disponível em: http:// www.portalsinan.saude.gov.br/dados-epidemiologicos-sinan. Acesso em: 12 jan. 2021.

MINAYO, M.C.D.S.; SOUZA, E.R.D.; SILVA, M.M.A.D.; ASSIS, S.G.D. Institucionalização 
do tema da violência no SUS: avanços e desafios. Ciência \& Saúde Coletiva, Rio de Janeiro, v. 23, n. 6, p. 2007-16, jun. 2018. Disponível em: https://www.scielo.br/pdf/csc/v23n6/1413-8123csc-23-06-2007.pdf. Acesso em: 12 dez. 2020.

PIRES, V.M.M.M.; MORAIS, R.L.G.L.; SANTOS, L.S.; MACHADO, J.C.; GUEDES, C.A.; RODRIGUES, V.P. Violência por parceiro íntimo em abuso de álcool perpetrada contra mulheres no climatério. Revista de Enfermagem da UFSM, v. 9, e45, p. 1-20, 2019. Disponível em: https:// periodicos.ufsm.br/reufsm/article/view/34201/pdf. Acesso em: 07 dez, 2020.

ORGANIZAÇÃO DAS NAÇÕES UNIDAS (ONU). Transformando nosso mundo: a agenda 2030 para o desenvolvimento sustentável. 2015. Disponível em: http://svs.aids.gov.br/dantps/acesso-ainformacao/acoes-e-programas/ods/publicacoes/transformando-nosso-mundo-a-agenda-2030-parao-desenvolvimento-sustentavel.pdf. Acesso em: 01 dez. 2020.

PROCENTESE, F.; NAPOLI, L.D.; TUCCIllO, F.; CHIURAZZI, A.; ARCIDIACONO, C. Healthcare professionals' perceptions and concerns towards domestic violence during pregnancy in Southern Italy. International Journal of Environmental Research and Public Health, v. 16, n. 3087, p. 1-17, 2019. Disponível em: https://www.mdpi.com/1660-4601/16/17/3087/htm. Acesso em: 11 jan. 2021.

SILVA, AC.F.; LOSACCO, A.M.; MONTEIRO, I.A. ABRAHÃO, A.R. Violência sexual por parceiro íntimo identificada em Unidade Básica do PSF. Nursing (São Paulo), v. 23, n. 263, p. 3705-9, abr. 2020. Disponível em: http://www.revistanursing.com.br/revistas/263/pg48.pdf. Acesso em: 17 jan. 2021.

SILVA, V. G.; RIBEIRO, P. M. Violência Contra as Mulheres na Prática de Enfermeiras da Atenção Primária à Saúde. Escola Anna Nery, Rio de Janeiro, v. 24, n. 4, p. e20190371, jul. 2020. Disponível em: https://www.scielo.br/pdf/ean/v24n4/1414-8145-ean-24-4-e20190371.pdf. Acesso em: 22 jan. 2021.

XAVIER, A.A.P.; SILVA, E.G. Assistência de enfermagem no atendimento de mulheres em situação de violência na atenção básica. REICEN-Revista de Iniciação Científica e Extensão, v. 2, n. esp. 2, p. 293-300, 2019. Disponível em: https://revistasfacesa.senaaires.com.br/index.php/iniciacaocientifica/article/view/279/217. Acesso em: 20 out. 2020.

MELO, M.C.G.D; RODRIGUES, A.S. Políticas de atendimento às mulheres em situação de violência doméstica: os centros de referência de atendimento às mulheres e a abordagem interseccional. $\mathbf{O}$ Social em Questão, v. 38, p.153-70, maio./ago., 2017. Disponível em: http://osocialemquestao.ser. puc-rio.br/media/OSQ_38_art_8_Melo_Rodrigues.pdf. Acesso em: 19 jan. 2021.

NASCIMENTO, V.F.; ROSA, T.F.L.; TERÇAS, A.C.P.; HATTORI, T.Y.; NASCIMENTO. V.F. Desafios no atendimento à casos de violência doméstica contra a mulher em um município matogrossense. Arquivos de Ciências da Saúde da UNIPAR, Umuarama, v. 23, n. 1, p, 15-22, jan./ abr. 2019. Disponível em: https://www.revistas.unipar.br/index.php/saude/article/view/6625/3725. 
Acesso em: 21 dez. 2021.

Ministério da Saúde. Decreto $\mathbf{n}^{\mathbf{0}} \mathbf{7 . 9 5 8}$, de 13 de março de 2013. Estabelece diretrizes para o atendimento às vítimas de violência sexual pelos profissionais de segurança pública e da rede de atendimento do Sistema Único de Saúde. Brasília (DF): Ministério da Saúde, 2013. Disponível em: http://www.planalto.gov.br/ccivil_03/DECRETO/D7958.htm. Acesso em: 22 jul. 2019. 